\title{
Arms Race Models and Econometric Applications
}

\author{
J. Paul Dunne, Eftychia Nikolaidou and Ron P. Smith* \\ Middlesex University Business School \\ and \\ *Birkbeck College, University of London
}

February 2000

\begin{abstract}
Richardson's action-reaction model of an arms race has prompted a considerable body of research which has attempted to empirically estimate such models. In general these attempts have been unsuccessful. This paper reconsiders the estimation issues using some recent developments in time-series econometrics, illustrating the issues with estimates for Greece and Turkey and India and Pakistan. Whereas there is little evidence for a Richardson type arms race for Greece and Turkey, India and Pakistan show a stable interaction with a well determined equilibrium.
\end{abstract}

Paper prepared for a conference on "The Arms Trade, Security and Conflict”, Middlesex University Business School, June 1999. We are grateful to Paul Levine for comments and Smith is grateful to the ESRC for support under grant R0002335685. 


\section{Introduction}

During the Cold War the arms race between the US and the USSR, which dwarfed all previous ones, was the focus of much concern. Since the end of the cold war the focus has shifted to regional antagonisms, but these are still analysed using arms race models developed during the Cold War. The standard framework for empirical study of arms races is the Richardson model described below which explains the time-series pattern of military expenditure between potential enemies in an action-reaction framework. A coupled pair of differential equations explains changes in levels of weapons in each of two nations as a function of the weapons of each side. Once the process has started no country is at fault, the escalation is a consequence of systemic interaction rather than aggression. Despite its popularity the results of the Richardson model has given disappointing results when applied to real data, as Sandler and Hartley (1995, p106-7) note. This is partly because there are real problems in moving from the abstract model to an empirical one. Any calibration requires decisions about the measurement of the variables, functional form, length of lags, and expectation formation that are not specified in the theory. There are also likely to be problems with the quality and reliability of the data which make their use questionable. In addition, the estimation of these models -forward looking, dynamic, simultaneous equation systems- presents its own set of issues and problems.

Recent developments in econometrics provide the opportunity to reconsider the empirics of arms race models and why they have been less than successful. This paper reviews the econometric issues and illustrates them by analysing the Greece-Turkey and India-Pakistan confrontations. Section 2 considers the basic Richardson model, its developments and the implications of unit roots and cointegration, covered in more detail in Smith et al (1999). Section 3 then analyses the arms race between Greece and Turkey within a VAR framework, illustrating the problems with this type of empirical analysis. Section 4 repeats the analysis for India and Pakistan. Finally, Section 5 provides some conclusions. 


\section{Econometrics Issues in Estimating Arms Race Models}

The 'structural form' of the familiar Richardson model can be written in discrete time with the addition of a stochastic error term as:

$$
\begin{aligned}
& \Delta \mathrm{m}_{1 \mathrm{t}}=\alpha_{1}+\beta_{1} \mathrm{~m}_{2 \mathrm{t}}+\gamma_{1} \mathrm{~m}_{1 \mathrm{t}-1}+\varepsilon_{1 \mathrm{t}} \\
& \Delta \mathrm{m}_{2 \mathrm{t}}=\alpha_{2}+\beta_{2} \mathrm{~m}_{1 \mathrm{t}}+\gamma_{2} \mathrm{~m}_{2 \mathrm{t}-1}+\varepsilon_{2 \mathrm{t}}
\end{aligned}
$$

where $m_{i t}$ is some measure of military preparedness of country $i$ in year $t(i=1,2)$. Richardson interpreted $\alpha_{i}(i=1,2)$ as exogenous 'grievance' terms, $\beta_{i}>0$ as 'reaction' terms and $\gamma_{\mathrm{i}}<0$ as 'fatigue' terms. We assume that:

$\mathrm{E}\left(\varepsilon_{\mathrm{it}}\right)=0, \mathrm{E}\left(\varepsilon_{\mathrm{i}}^{2}\right)=\sigma_{\mathrm{i}}{ }_{\mathrm{i}}, \mathrm{E}\left(\varepsilon_{\mathrm{it}} \varepsilon_{\mathrm{jt}}\right)=\sigma_{\mathrm{ij}}, \mathrm{E}\left(\varepsilon_{\mathrm{it}} \varepsilon_{\mathrm{jt}-\mathrm{s}}\right)=0$, where $\mathrm{s} \neq 0$ and $\mathrm{i}, \mathrm{j}=1,2$.

These structural shocks, $\varepsilon_{\text {it }}$, will be driven partly by idiosyncratic factors (events in former Yugoslavia and the Balkans in general for Greece and the conflict with the Kurds for Turkey) and partly by common factors (events in the former Soviet Union or NATO modernisation or both). So, we would not expect the structural shocks to be independent.

This form is structural in that current values of the endogenous variables appear on the right hand side of the equation. Sets of equations with this general form can be derived from a variety of different theories, e.g. see the discussion in Brito and Intriligator (1995) or Levine and Smith (1997). The structural parameters, $\alpha_{i} \beta_{i}$ and $\gamma_{i}$ , will be functions of the deep parameters of the system. For instance in Levine and Smith (1997), they are functions of depreciation rates for weapons, strategic parameters which describe the nature of conflict, discount rates, and the elasticity of substitution between security and consumption. Even if one can estimate the structural parameters consistently, this may not allow one to recover the underlying deep parameters.

The reduced form of the system, in terms of predetermined, lagged variables can be written in the VECM (Vector Error Correction Model) form of a first order VAR (Vector Autoregression) as: 


$$
\begin{aligned}
& \Delta \mathrm{m}_{1 \mathrm{t}}=\delta_{11}+\delta_{12} \mathrm{~m}_{1 \mathrm{t}-1}+\delta_{13} \mathrm{~m}_{2 \mathrm{t}-1}+\mathrm{u}_{1 \mathrm{t}} \\
& \Delta \mathrm{m}_{2 \mathrm{t}}=\delta_{21}+\delta_{22} \mathrm{~m}_{1 \mathrm{t}-1}+\delta_{23} \mathrm{~m}_{2 \mathrm{t}-1}+\mathrm{u}_{2 \mathrm{t}}
\end{aligned}
$$

where $\mathrm{E}\left(\mathrm{u}_{\mathrm{it}}\right)=0, \mathrm{E}\left(\mathrm{u}_{\mathrm{i}}^{2}\right)=\omega_{\mathrm{i}}^{2}, \mathrm{E}\left(\mathrm{u}_{\mathrm{it}} \mathrm{u}_{\mathrm{jt}}\right)=\omega_{\mathrm{ij}}, \mathrm{E}\left(\mathrm{u}_{\mathrm{it}} \mathrm{u}_{\mathrm{jt}-\mathrm{s}}\right)=0$, where $\mathrm{s} \neq 0$ and $\mathrm{i}, \mathrm{j}=1,2$. Smith et al (1999) discuss the relationship between the two forms. There is Granger (1969) causality from $\mathrm{m}_{1}$ to $\mathrm{m}_{2}$ if $\delta_{22} \neq 0$ and from $\mathrm{m}_{2}$ to $\mathrm{m}_{1}$ if $\delta_{13} \neq 0$. Each equation of the reduced form can be estimated consistently by least squares.

In the theory the military expenditure variables are treated as stationary variables, integrated of order zero $\mathrm{I}(0)^{1}$. If the variables are $\mathrm{I}(1)$, or equivalently contain a stochastic trend, then there is a danger of spurious regression. In a regression of one I(1) variable on another, the $R^{2}$ tends to unity with the sample size and the $t$ ratio to a non zero value, even if the two series are unrelated. The requirement for the regression not to be spurious is that the two variables cointegrate. If this is the case then the process can be represented as a restricted form of the error correction model above. If the long run relationship is $\mathrm{m}_{1 \mathrm{t}}=\beta \mathrm{m}_{2 \mathrm{t}}$ then the disequilibrium or error correction term is measured by $z_{t}=m_{1 t}-\beta m_{2 t}$. The VECM then takes the form:

$$
\begin{aligned}
& \Delta \mathrm{m}_{1 \mathrm{t}}=\delta_{11}+\alpha_{1} \mathrm{z}_{\mathrm{t}-1} \\
& \Delta \mathrm{m}_{2 \mathrm{t}}=\delta_{21}+\alpha_{2} \mathrm{z}_{\mathrm{t}-1}
\end{aligned}
$$

where the feedbacks are stabilising if $\alpha_{1}<0, \alpha_{2}>0$. Estimation and testing of the cointegrating vectors can be done in a number of ways, including within the maximum likelihood framework suggested by Johansen (1988).

Unit root tests and cointegration have been widely adopted, Kollias and Makrydakis (1997) is an arms race example. However, there are a number of problems with the techniques. Both the tests for unit roots (used to determine the order of integration) and the tests for cointegration tend to have low power, so determining the order of integration and cointegration is not straightforward. The tests are also sensitive to the

\footnotetext{
${ }^{1}$ A variable is said to be $I(d)$, integrated of order $d$, if it must be differenced $d$ times to become covariance stationary. A variable is said to be covariance stationary if its expected value, variances and autocovariances are all constant, perhaps after the removal of a deterministic
} 
choice of lag order, the treatment of serial correlation, the treatment of the deterministic elements, the presence of structural breaks and various other factors. There are also questions of interpretation, since the order of integration is not a structural property of the series but a description of the time-series properties of a sample. Series which appear I(1) on short spans of data often appear I(0) on long spans, where span refers to the length in time of the series not the number of observations. Over centuries of data, the UK share of military expenditure is clearly I(0), over shorter spans it appears to be I(1). While cointegration allows us to estimate the long-run equilibrium, it does not help in identifying the short-run structural interaction.

A major problem with the Richardson model is the lack of a budget constraint. This can be dealt with by, for example, including GDP to reflect income. Care needs to be taken in including variables within a VAR, however, as the number of parameters grows very rapidly with the number of variables and the number of lags and the small sample properties of large VARs are rather poor. In addition, inference, e.g. Granger Causality tests, tends to be sensitive to specification, including or excluding variables can change the results. However, adding income may provide more plausible identifying restrictions. For instance, it is possible that countries adjust their military expenditure in response to their own GDPs, but not to the other countries GDP, or have an arms race in shares of military spending in GDP (military burdens).

There is a variety of interesting testable system restrictions on the VAR, e.g. exogeneity of income, levels versus shares. In principle, starting from a general system and testing system wide restrictions is an appropriate way to develop a model of the arms race process. In practice, it can be difficult to find theoretically coherent and statistically acceptable specifications on a large system through such a procedure. Ad hoc deletion of individual insignificant coefficients is also unsatisfactory because what look like acceptable single equation restrictions can produce unacceptable systems properties. A further consideration is the expectations process, which is left, unspecified in the theoretical model. Within the framework discussed above there are a number of possible interpretations, which are discussed in Smith et al (1999).

trend. An I(0) variable is thus stationary. 
Having briefly outlined the issue we now consider two applications, Greece-Turkey and India-Pakistan. In any empirical application we have to determine:

(a) The number of variables analysed, military expenditures alone or with income.

(b) The transformation of the variables. Linear or logarithmic for instance.

(c) The order of integration of the variables.

(d) The order of the VAR, number of lags included.

(e) The treatment of deterministic elements, dummy variables, trends and intercepts, in the cointegrating VAR.

(f) The number of cointegrating vectors

(g) The just identifying restrictions required to interpret the cointegrating vectors and any overidentifying restrictions.

As we shall see, this gives a large possible parameter space to search over.

\section{The Greece-Turkey Arms Race}

There is considerable debate over the Greece-Turkey arms race as previous studies have given mixed results. Majeski and Jones (1981) and Majeski (1985) using causality analysis, tested for interdependence in the military expenditures of Greece and Turkey for 1949-1975 and their results indicated the presence of instantaneous causality. Kollias (1991) applied the classical Richardson model for the two countries over the periods 1950-1986 as well as over 1974-1986 (the period after the Turkish invasion of Cyprus), but his results were very poor and did not indicate the existence of an arms race. However, by employing specific indices of military capabilities, he found that Greek military expenditure depends on Turkish military expenditure and on the relative size of the arms forces. Also, Kollias and Makrydakis (1997), using cointegration and causality tests, found evidence of a systematic armaments competition between Greece and Turkey over the period 1950-1995. Refenes et al. (1995) using neural networks and indices of military capabilities (ratio of armed forces and military expenditures per soldier) examined the hypothesis of an arms-race between Greece and Turkey over 1962-90 and found that Turkey's quantitative advantage is the most significant external security determinant of Greek military expenditure. 
On the other hand, there are studies that do not provide strong evidence of an armsrace between the two countries. Georgiou (1990) tested the hypothesis of an armsrace over the period 1958-1987 but could not find any evidence of the existence of an arms-race and Georgiou, Kapopoulos and Lazaretou (1996) using a vector autoregression specification ended up with similar conclusions for the period 196090 .

Figure 1: Military Expenditure for Greece and Turkey*

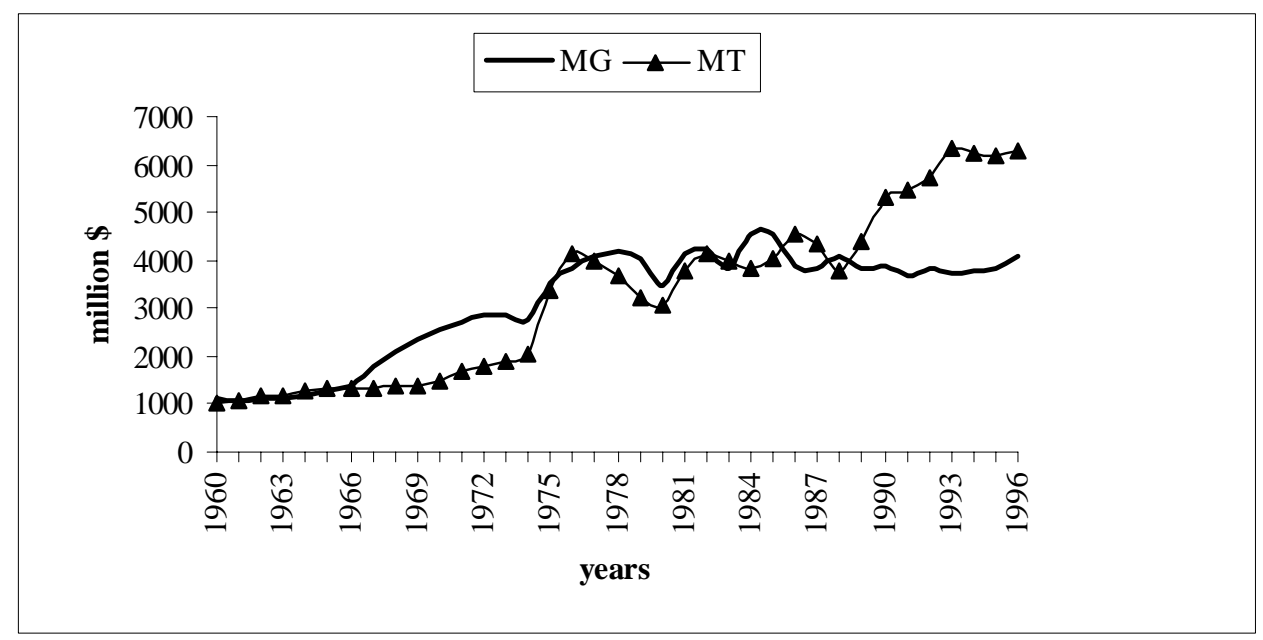

*in constant 1990 million US \$

Source: SIPRI Yearbooks

Using SIPRI data (see Figure 1) on military expenditure for the two countries a VAR model of the arms race was specified ${ }^{2}$. Initial tests for unit roots showed the series to

\footnotetext{
${ }^{2}$ There were some problems with the data as the Turkish GDP were revised and this led to some quite marked changes in the SIPRI estimated shares. Specifically, in 1998 SIPRI Yearbook the shares are much smaller than those reported in previous Yearbooks. This difference in the shares figures is not
} 
be I(1). The Turkish invasion of Cyprus had a marked impact on Greek Turkish relations and this is modeled by a step dummy $C D$, which takes the value of 0.5 in 1974, of 1.0 for 1975-9 and zero otherwise. Non nested tests indicated that equations using the logarithms of the data fit better than ones using untransformed data. Starting from a lag length of 5, using the logarithms of military expenditure and using CD as an exogenous variable, adjusted Likelihood Ratio (LR) tests and the Schwarz Bayesian Criterion (SBC) indicate a first order VAR, though the Akaike Information Criteria (AIC) and unadjusted LR tests suggest longer lags. Given the length of the time series we continue with a VAR(1) and investigate whether or not the variables are cointegrated.

Using a first order VAR with unrestricted intercepts and restricted trends over 1961 to 1996, trace and eigenvalue tests suggested one cointegrating vector at the $5 \%$ level between the logarithms of military expenditures. Normalising on the log of Greek military spending, LMG, the cointegrating vector was:

$$
\mathrm{LMG}_{\mathrm{t}}=-29.1 \mathrm{LMT}_{\mathrm{t}}
$$

plus trend and Cyprus dummy. This has the wrong sign on the logarithm of Turkish military spending. All the results were very sensitive to specification and sample period, suggesting that the estimates are fragile.

One possible source of mispecification is failure to take account of the budget constraint. To consider this a VAR model in the logarithms of military expenditure and GDP (which were calculated from SIPRI figures for military expenditure and shares), was estimated. All variables were tested for unit roots and were found to be I(1) and non-nested tests again suggested that the logarithmic equation fit better than the untransformed equation. In this case the SBC indicated a second order VAR. A joint Likelihood ratio test for the exclusion of the GDP variables $\chi^{2}(8)=42.9$, which is well above the $5 \%$ critical value, suggesting that income is important. Assuming unrestricted intercepts and restricted trends in a VAR(2) with the Cyprus Dummy over 1962-1996, trace and eigenvalue tests again suggested one cointegrating vector. 
Again normalising on Greek Military expenditure gave the cointegrating vector:

$\mathrm{LMG}_{\mathrm{t}}=4.01 \mathrm{LMT}_{\mathrm{t}}+0.70 \mathrm{LYG}_{\mathrm{t}}-1.38 \mathrm{LYT}_{\mathrm{t}}$

plus trend and Cyprus dummy. This has the right signs but an implausibly large coefficient on Turkish military expenditure. It is possible that this is a relation in shares and this was tested by imposing the implied over-identifying restrictions. This gave:

$(\mathrm{LMG}-\mathrm{LYG})=4.98(\mathrm{LMT}-\mathrm{LYT})$

plus trend and Cyprus dummy . Again the coefficient on the logarithm of the share of Turkish military expenditure is implausibly large. The share restrictions were rejected by the data $\chi^{2}(2)=12.8$. The VECM estimates for the just identified system ( $\mathrm{t}$ ratios in brackets) are:

$$
\begin{aligned}
& \Delta \mathrm{G}_{\mathrm{t}}=2.42+0.10 \Delta \mathrm{G}_{\mathrm{t}-1}-0.06 \Delta \mathrm{T}_{\mathrm{t}-1}-0.58 \Delta \mathrm{Y}_{\mathrm{t}-1}-0.26 \Delta \mathrm{TY}_{\mathrm{t}-1}+0.10 \mathrm{Z}_{\mathrm{t}-1}+0.12 \mathrm{CD}_{\mathrm{t}} \\
& \begin{array}{llllll}
(2.74) & (0.55) & (0.39) & (2.17)
\end{array}
\end{aligned}
$$

$$
\begin{aligned}
\Delta \mathrm{T}_{\mathrm{t}}= & 5.10-0.27 \Delta \mathrm{G}_{\mathrm{t}-1}+0.37 \Delta \mathrm{T}_{\mathrm{t}-1}-0.59 \Delta \mathrm{Y}_{\mathrm{t}-1}-0.62 \Delta \mathrm{TY}_{\mathrm{t}-1}+0.21 \mathrm{Z}_{\mathrm{t}-1}+0.24 \mathrm{CD}_{\mathrm{t}} \\
& (6.83)(1.86)
\end{aligned}
$$

$\mathrm{R}^{2}=0.69 ; \mathrm{SER}=0.07$

There are also equations for GDP which we do not report. For the Greek equation, four of the seven coefficients are significant at the $5 \%$ level. The coefficients on the error correction term, lagged Z, measure the speed at which any disequilibrium is removed, though the adjustment in the Greek case is in the wrong direction. The specification easily passes the tests for first order serial correlation, functional form, normality and heteroscedasticity. The equation for Turkey is a better specification in terms of the coefficient estimates, with six of the seven significant, but fails the tests 
for functional form $\chi^{2}(1)=7.68$. Cusum and Cusum squared tests suggest structural stability, while the persistence profiles to system wide shocks are fairly similar, The persistence profile of system wide shocks to the CVs show a relatively fast convergence, around 3 years.

Again there seems to be some evidence of a cointegration, but not in the form of a long run arms race model. Experiments with a variety of different formulations did not reveal a robust arms race relationship. The results tended to be difficult to interpret and extremely sensitive to sample and specification. Given their antagonistic interaction and their reactions to each others military preparations, there has undoubtedly been an arms race between Greece and Turkey. But that arms race has not taken the form of stable Richardson type reaction functions. Given all the other factors intervening in their interaction, this is not perhaps surprising.

\section{The India-Pakistan Arms Race}

Unlike Greece and Turkey where the literature is ambiguous, previous studies of India and Pakistan e.g. Deger and Sen (1990) have found evidence of a Richardson type arms race in the sub-continent. Given the results for Greece-Turkey, the starting point for India and Pakistan was a VAR in military expenditures and GDP. The GDP figures were again calculated from the SIPRI figures for military expenditures (see figure 2 for the levels of military expenditure) and shares.

\section{Figure 2. Military Expenditure for India and Pakistan*}

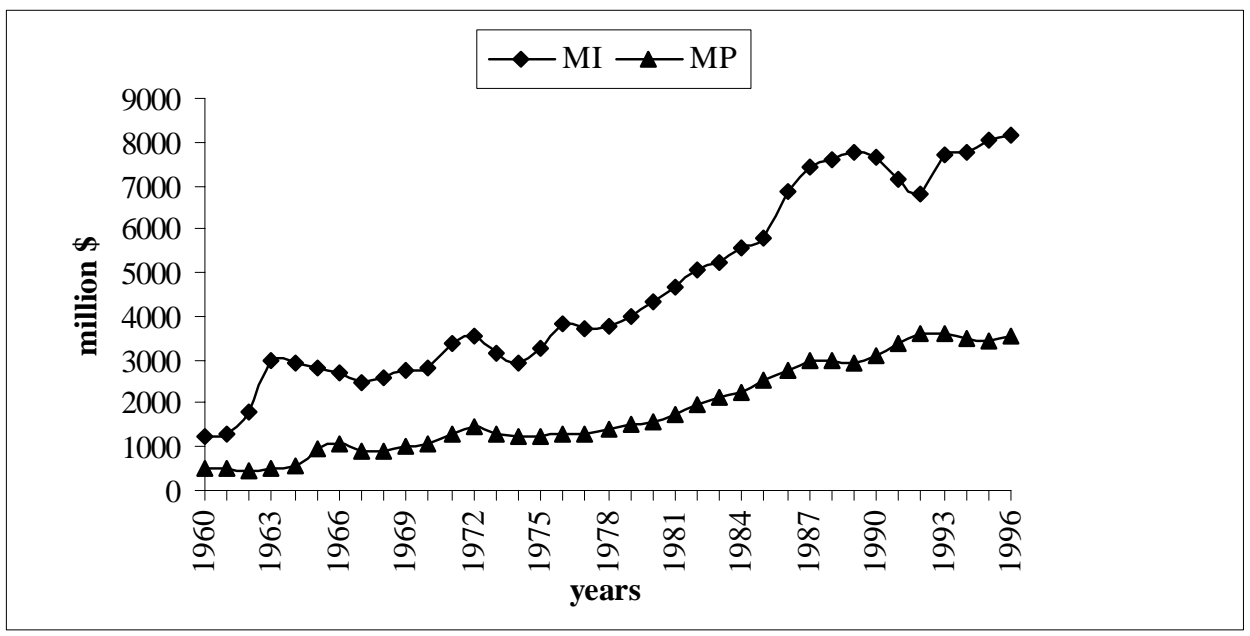

*in constant 1995 million US \$ 
All these variables appear to be I(1), though shares of military expenditure in GDP appear to be I(0). Both model selection criteria and Likelihood Ratio tests indicate that a second order VAR is appropriate. Both non-nested tests and likelihood criteria indicated that a linear model fits better than a logarithmic one. In the linear second order VAR in the four variables, the Likelihood Ratio test statistic for the hypothesis that the income variables do not appear in the military expenditure equations is 15.4. This is just below the asymptotic $5 \%$ critical value for a $\chi^{2}(8)$, which would be appropriate if the variables were stationary. Given that the small sample critical values for non-stationary variables would be rather larger, this suggests that we can treat the income variables as Granger non-causal with respect to military expenditures and work with a two variable VAR. There is an element of judgement in this, since the theory suggests that income should be included to capture the budget constraint and some income variables are individually significant in the Indian military expenditure equation.

Using unrestricted intercepts and no trends (which were insignificant) in a second order VAR, 1962 1996, the trace and eigenvalue tests both clearly suggest one cointegrating vector at the $5 \%$ level. The eigenvalue test statistic is $26.3,5 \%$ critical value 14.9, trace 26.4 and 17.9. Normalising on Indian Military Expenditure the cointegrating vector is $\mathrm{MI}_{\mathrm{t}}=2.008 \mathrm{P}_{\mathrm{t}}$ which indicates that the long-run relationship is for India to spend about twice the Pakistani level.

The estimated VECM (with t ratios) is:

$$
\begin{aligned}
& \Delta \mathrm{I}_{\mathrm{t}}=469.0+0.43 \Delta \mathrm{I}_{\mathrm{t}-1}-0.08 \Delta \mathrm{P}_{\mathrm{t}-1}-0.37 \mathrm{Z}_{\mathrm{t}-1} \\
& \text { (3.36) (2.41) (0.17) (2.70) } \\
& \mathrm{R}^{2}=0.23 ; \mathrm{SER}=343.0 \\
& \Delta \mathrm{P}_{\mathrm{t}}=-62.0-0.11 \Delta \mathrm{I}_{\mathrm{t}-1}+0.438 \Delta \mathrm{P}_{\mathrm{t}-1}+0.14 \mathrm{Z}_{\mathrm{t}-1} \\
& \text { (1.45) (2.05) (3.07) (3.36) } \\
& \mathrm{R}^{2}=0.37 ; \mathrm{SER}=105.0
\end{aligned}
$$


Apart from the intercept in the Pakistan equation and lagged Pakistani spending in the Indian equation all the coefficients are significant. Both equations pass tests for first order serial correlation, non-linearity, normality and heteroscedasticity at the $1 \%$ level; though Pakistan fails on normality and India on heteroscedasticity at the 5\% level. Cusum and Cusum squared tests indicate that both equations are structurally stable. In terms of changes the degree of explanation is low, though the equations explain over $95 \%$ of the levels of military expenditure. The coefficients on lagged Z, which measure the speed at which disequilibria are removed, are both of the correct sign and indicate that India adjusts to disequilibrium faster than Pakistan. There seems to be a degree of over-reaction, represented by the negative coefficients on the other countries lagged changes. Convergence back to equilibrium is cyclical, but quite rapid, with adjustment complete in about six years. There is quite a high positive correlation $(\mathrm{r}=0.46)$ between the errors in the two equations, indicating a degree of instantaneous feedback. Unlike the Greece-Turkey case, the results seem quite robust and not very sensitive to sample or the details of specification.

\section{Conclusions}

This paper has considered some of the econometric issues involved in estimating arms race models and has illustrated the problems using the examples of Greece and Turkey and India and Pakistan. At a common-sense level one would regard both dyads as being involved in arms races, yet in one case it takes the classical Richardson form and in the other it does not. In the case of Greece and Turkey estimating a VAR with the logarithms of military spending and income for the two countries fails to find any reasonable result. In contrast estimating a VAR for India and Pakistan is much more straightforward. There is one cointegrating relation between the two countries which suggests that the long run relationship is for India to have twice as much military spending as Pakistan. Whereas Greece-Turkey estimates seem fragile, India-Pakistan estimates seem robust.

Why there should be such differences between the two cases is unclear. There are a 
number of possibilities. Firstly the difference may reflect the security environment. Turkey and Greece might be considered to be in a more complex environment. Both are members of NATO and alliance effects, e.g. Murdoch (1995) may be important. Both have other security concerns apart from each other. Both faced a Soviet threat for much of the sample and Turkey has faced a continuing Kurdish question. India and Pakistan might be considered a more straightforward confrontation between two states. However, India has confronted China and Pakistan has had disputes with Afghanistan and Bangladesh. Secondly, the difference may reflect different government and decision making structures. Following the British model both India and Pakistan have similar decision making processes which may make them react consistently to changes in their protagonists military spending. This would make them more amenable to modeling than Greece and Turkey with their very different state structures and history. Thirdly, rivalry takes many different forms and there may be substitution between alternative instruments of rivalry depending on the strategic and political situation. This may mean that the optimal response to military spending by the other country may investment in some other instrument than military spending, e.g. support for terrorism in the other country. An interesting issue is whether the historical reaction functions between Indian and Pakistan remain stable following their nuclear explosions, which may change the form of rivalry. Finally, the data are not very reliable and are possibly massaged by the states for their own purposes. However is not clear why this should explain the difference in reaction functions for the two cases.

\section{References}

Brito, D.L. and M.D. Intriligator (1995) Arms Races and Proliferation, Chapter 6 of Handbook of Defence Economics, ed. K. Hartley and T. Sandler, Elsevier Science.

Deger, S. and Sen, S. (1990) Military Security and the Economy: Defence Expenditure in India and Pakistan, Chapter 9 of K. Hartley and T. Sandler (eds) The Economics of Defence Spending, Routledge, London, pp189-227.

Georgiou, G., Kapopoulos, P. and Lazaretou, S. (1996) Modelling Greek-Turkish Rivalry: An Empirical Investigation of Defence Spending Dynamics, Journal of Peace Research, 33(2), 229-239 
Georgiou, G. (1990) Is there an Arms Race between Greece and Turkey? Some Preliminary Econometric Results, Cyprus Journal of Economics, 3(1), 58-73

Granger C.W.J. (1969) Investigating Causal Relations by Econometric Models and Cross-Spectral Methods, Econometrica, July, 424-38.

Johansen, S., (1988) Statistical analysis of cointegrating vectors, Journal of Economic Dynamics and Control, 12, 231-254.

Kollias C. and Makrydakis, S. (1997b) Is there a Greek-Turkish Arms Race?

Evidence from cointegration and causality tests, Defence and Peace

Economics. 8 (4) 355-379.

Kollias, C. (1991) Greece and Turkey: The Case Study of an Arms Race from the Greek Perspective, Spoudai, 41(1), University of Piraeus, 64-81.

Levine P and R.P. Smith (1997) The arms trade and the stability of regional arms races, Journal of Economic Dynamics \& Control, 21, 631-654.

Majeski, S. and Jones, D. (1981) Arms Race Modelling. Causality Analysis and Model Specification, Journal of Conflict Resolution, 25, 259-288

Majeski, S. (1985) Expectations and Arms Races, American Journal of Political Science, 29, 217-245

Murdoch, J.C. (1995) Military Alliances: Theory and Empirics, Chapter 5 of Handbook of Defence Economics, ed. K. Hartley and T. Sandler, Elsevier Science.

Refenes, A.N., Kollias, C. and Zarpanis, A. (1995) External Security Determinants of Greek Military Expenditure: An Empirical Investigation using Neural Networks, Defence and Peace Economics, 6, 27-41.

Sandler, T. and Hartley, K. (1995) The Economics of Defense, Cambridge, Cambridge University Press.

Smith, R.P., Dunne, P. and Nikolaidou, E. (1999, forthcoming) The Econometrics of Arms Races, Defence and Peace Economics. 